\title{
Serviços públicos de saúde e medicina alternativa
}

\author{
Public health care and alternative medicine
}

Islândia Maria Carvalho de Sousa 1

Ana Luiza Stiebler Vieira 2

* Arti go ex traído

da dissertação de mestrado

da primeira autora sob

ori entação da segunda

a utora na Escola Nacional

de Saúde Pública Sergio

Arouca, Fiocruz.

${ }^{1}$ Programa Sa úde

da Família em Exu (PE)

e Planejamento

em Bodocó (PE).

Av. Edmundo Dantas 269,

Cen tro, 56230-000, Exu PE.

ismcs@hotmail.com

2 Escola Nacional

de Saúde Pública Sergio

Arouca, Fiocruz.
Abstract This study of a case with a qualitative approach has the main objective the analysis of massage practice of fered by the Al ternative Medicine program at Rio de Ja nei ro County. It is limited by the programmatic area 3.1 (Leopoldina Area), where this program was implemented, and this practice has been utilized in four services of distinctive complexity. Trough the participant observation, of in terviews, and the analysis of user's records, we have verified the sort and knowledge used by this practice, the profiles of users and professionals, based in the oriental paradigm, has be en captu red by the bi o m edical rationality, nevertheless, the benefits related by users, are expressive; there is a expansion and demand diversification and the causes and orientation. We believe that this practice could be, in fact, an alternative to the care and an improvement at the SUS assistance.

Key words Alternative medicine, Massage, Public health
Resumo Este estudo de caso com abordagem qualitativa teve como objetivo cen tral analisar a prática da massagem ofertada pelo Programa de Med i cina Al terna tiva do município do Rio de Janeiro. Limita-se à área programática 3.1 (zona da Leopoldina), onde o programa foi implantado e a prática vem sendo realizada em quatro serviços de complexidade distinta. Por meio da observação participante, de entrevistas, e da análise das fichas dos usuários, verificamos as modalidades e os conhecimen tos utilizados para esta prática, o perfil dos profissionais e dos usuários, e ainda, os motivos ou indicações. Os re sultados revela ram que a massagem, fundamentada no pa radigma vitalista, tem sido captada pela racionalidade biomédica, mas os ben efícios relatados pelos usuários são expres s ivos; há expansão e diversificação da demanda e dos motivos e ou encaminhamentos. Acreditamos que esta prática pode ser, de fato, uma alternativa de atendimento $e$ melhoria da assistência no SUS.

Palavras-chave Medicina alternativa, Massagem, Saúde pública 


\section{Introdução}

Observa-se atualmen te o crescimento de "medicinas alternativa s" nos serviços de saúde, no s etor econ ômico e na mídia. Elas vêm ocupando espaço tanto nas classes sociais mais favorecidas qu a n tonas menos favorecidas. Seja como material de especulação, opção terapêutica ou obj eto de estu do no meio científico.

As medicinas alternativas estão apoiadas em um paradigma vitalista. Tal paradigma revela a existência de uma "dinâmica vital", algo que está além do corpo físico. É através do fluxo desta "dinâmica vital" que se determina o estado de saúde ou doença (Luz, 1996). Para a medicina tradicional chinesa, por exemplo, a doença é fruto do desequilíbrio do Qİ, KI ou CHÍ, tradu zi dopor alguns autores como "energia vital" ( Bon tem po, 1994; Jacques, 1999; Freire, 1996; 1993). Tal fato é considerado um equívoco por Luz (1993), que traduz o Qİ como "sopro vital" ou "s opro", que pode assemelharse ao vento, à respiração, ao ar, ao vapor. Deste modo, a tradução para "energia vital" viria da nossa dificuldade de compreender a essência da medicina tradicional chinesa (MTC), pois a ela é um sistema terapêuti co completo, possuin do uma cosmologia distinta da nossa medicina ocidental.

Há nas medicinas alternativas uma teoria que a vida se apresenta em movimento, "sopro", "dinâmica vital", "energia", "bioenergi a", afirmando a necessidade de um princípio que não seja apenas material (físico-químico), para explicar os fen ô menos vitais. Nestas medicinas, a doença é o resultado de um desequilíbrio de forças naturais e sobren aturais, com preendida como o rompimen to da harmonia com a ordem cósmica em movimen to (Luz, 1996). Essa visão dos seres humanos e do ambiente como sendo inseparávés e co-extensivos com o universo é um com pon en te fundamental das principais filosofias ori entais (Godoy, 1988; Svoboda \& Lade, 2000). Ao contrário do que ocorre no Ocidente, médicos orientais podem aceitar juízos subjetivos seus e do doen te, s em que vejam nisso uma ameaça à sua competência. Eles possu em a consciência que estão lidando com sistemas vivos, em fluxo contínuo, em relação aos quais o valorda ex periência subjetiva é tão precioso quan toà avaliação raci onal (Capra, 1998).

Nesse sentido, as práticas de medicina alternativa, que em sua grande maioria provêm das culturas orientais têm um caráter menos in tervencionista. Em vez de se opor à doença, de impedir certas manifestações sintomáticas, tenta-se compreen der suas causas buscando envolver o indivíduo e o seu modo de vida. A ênfase é dada ao doen te e não à doença. Passar por fases temporárias de doença nas quais se pode aprender e crescer é estar em equilíbrio dinâmico. Nesse caso, os períodos de saúde precária são estágios natu rais de interação contínua entre o indivíduo e o ambiente (Queiroz, 2000). A prática de medicinas alternativas desempenha um papel simbólico, de ordenação de significados, e prático, possibilitando a incorporação de diferentes especialistas. Mas também exerce o papel político na medida em que defende os saberes deslegitimados pelo m odelo de saúde oficial (Loyola, 1987; 1991).

A medicina alternativa também pode ser apresentada como uma tec nologia leve, de acordo com Merhy (1994), que classifica as tecnologias em saúde comoleves, leves-duras e duras. A tecnologia aqui não está totalmente vinculada a um equipamen to tecnológico, mas também ao "saber fazer", e um "ir fazen do", que dão s en ti do ao que será ou não a razão instru mental do equipamento. Segun do o mesmo autor, ela se faz no trabalho vivo en tre o profissional e o usu ário. De stemodo, a tecnologia leve é a maneira de cuidar e tratar o usuário: A tecnologia está nos diferentes saberes que procuram ler o nosso mundo humano do ponto de vista da saúde e da doença, do normal e do patológi co, da vida e da morte, procurando construir procedimentos eficazes de intervenção nestes processos... Podemos dizer que a medicina oriental é tão tecnológica quanto a ocidental alopática, pois ela além de desenvolver toda uma leitura, em nós, sob re saúde e doença, cria processos de trabalhos específicos pa ra intervir nestas dimensões (Merhy, 1994) (gri fos meus).

No município do Rio de Janeiro, vêm sendo implantadas diversas práticas alternativas nos serviços de saúde, por meio do Programa de Medicina Alternativa. E, em particular, a prática da massagem, objeto de nossa investigação. O termo massagem é em pregado nesse estudo para denominar as práticas manuais utilizadas como instrumen to na obtenção da saúde e bem-estar. As sumimos que o emprego dessa categoria é limitado por não caracterizar todas as modalidades terapêuticas, principalmente as práticas provenientes de culturas orientais. No entanto, a mesma já está consagrada, e constitui uma prática que predominantemente tem as mãos como meio de aplicação, sem o uso de artifícios mecânicos. Das prá- 
ticas de massagem vistas como altern a tivas, fundamentadas no paradigma vitalista, algumas são mais comuns no Brasil: o Tuiná e Tuiná para crianças, o Do-in, a Reflexologia, o Shiatsu, a Shantalae a massagem Ayu rveda. Com exceção desta última, todas as outras modalidades de massagem estão pres en tes no Programa de Medicina $\mathrm{Al}$ tern a tiva.

Es tu dos sobre a incorporação dessa prática nos serviços públicos ainda são escassos. Sua expansão nos serviços municipais do Rio de Janei ro é recente, não havendo investigações a respei to. Todavia, partimos do pressupo sto que a expansão da massagem não significa nece ssariamente uma mudança na assistência, pois as práticas fundamen tadas no paradigma vitalista têm sido captadas pela racionalidade biomédica e em pregadas segundo os precei tos desta.

Assim, e s te estu do teve como obj etivo central analisar a prática da massagem oferecida pelo referido programa nos serviços públicos de saúde. Para tal, verificamos nos serviços as modalidades de massagem ofertadas, os conhecimen tos utilizados para esta prática, os profissionais que a exerciam, no que con cerne à sua formação e vínculo profissional e, ainda, i dentificamos a demanda atendida em relação aos encaminhamentos e o seu perfil de gênero, idade e motivos ou indicações para utilização da massagem.

Esse estu do de caso com abord a gem qualitativa está limitado à área progra má tica 3.1 (zona da Leopoldina) devi do ao seu histórico, pois foi nesta área onde primeiro se implantou o programa no município, em 1992. A zona da Leopoldina possui peculiar diversidade cultural, social e econômica. Aí, a prática é realizada em qu a tro serviços de complexidade distinta (ambulatório de um hospital de emergência, uma policlínica e dois pos tos de assistência médica).

A prática de massagem foi acompanhada por meio da observação participante nos quatro serviços de saúde; foram entrevistados os cincoprofissionais que realizavam a massagem e a gerente do programa, utilizando-se um questionário semi-estruturado; e ainda, anali$\mathrm{s}$ adas as fichas cadastrais dos usuários atendidos no período de julho de 2002 a julho de 2003. Foram utilizados os dados do diário de campo registrados duran te a ob servação participante, realizada de feverei ro a setembro de 2003, na qual houve a participação e observação de todas as atividades de envolvidas pelos massotera peutas (caminhadas pelo parque, of icinas de relaxamento; ginástica e massagens).
Participamos, ainda, de dois eventos realizados pelos massoterapeutas e a gerente. Ao sermos apresentados aos usuários, alguns desejaram s em a nossa solicitação - fazer um relato de sua ex periência. Tais rel a tos foram gravados e analisados.

\section{Conhecen do a prática da massagem na A.P. 3.1}

\section{O rganização dos serviços e atendimen to}

Em cada unidade, as atividades ligadas à massagem assumiam características diferentes e, a nosso ver, associadas à formação e anteceden tes dos profissionais que as realizavam. A dinâmica do serviço tendia a ser mais forte que a prática de medicina alternativa. Ao mesmo tempo, percebemos que existiam profissionais que superavam esta dico tomia transformando o ambi ente desfavorá vel. Tinham liberd ade de escolher de que manei ra realizariam seu trabalho, sen do a estrutura do setor favorável ou não. Eles realizavam outras atividades além da massagem, como a ginástica, a auriculoterapia, caminhada, palestras e oficinas de relaxamento.

Com relação à sala de espera, cada unidade era ad a ptada de acordo com sua realidade. Em uma delas, enquanto aguard avam o atendimen to, os usuários recebiam um massageador para os pés e, sentados, se massage avam. Não havia regras gerais para selecionar o tipo de tratamento para o usuário, caben do ao profissional a avaliação e indicação do tratamento: massagem, auriculoterapia, caminhada, ginástica, podendo ser indicado mais de um para o mesmo usuário. Pa ra a massagem e a auriculoterapia, após um mínimo de dez sessões, realizava-se nova avaliação para verificar a necessidade de mudança ou continuidade do tratamen to.

Não havia normas para produção, isto é, $n$ ú $m$ ero específicode atendimento/dia. $\mathrm{O}$ atendimento durava no máximo 30 minutos. Os procedimentos eram informados como atividades de gru po para constar no sistema de informações da unidade. O banco de dados sobre a massagem dependia fundamentalmen te das fi chas cad astrais utilizadas pelos prof is si onais e dos relatórios mensais enviados para a geren te do programa. Observamos que, ao preencher o relatório, ele era interpret ado de forma distinta pelos profissionais, fato constatado também, na estatística cen tral. 
Em um dos serviços, numa mesma sala o profissional atendia várias pessoas ao mesmo tempo. Os usu á rios pareciam não se incomodar. Durante $o$ atendimento, ficavam conversando entre si sobre o tratamento, haven do bastante in teração no grupo. Contavam brincadeiras e experiências com o tratamento. O profissional realizara a reflexologia em uma usuária, depois massagem su eca em outra, sen do possível ob servar duas prá ticas de racionalidades distintas no mesmo espaço. Esse modo de realizar a massagem pode ser posi tivo na medida em que favorece a interação en tre os usuá rio s. Con tudo, esse tipo de assistência pode impedir que pessoas mais tímidas possam aderir ao tratamento, bem como dificultar uma assistência individualizada.

\section{Realização da massagem}

Um fato interessanteque pôde ser observado foi a grande adesão dos massoterapeutas à auriculoterapia, sendo a prática mais utilizada, s eguida da ginástica, refl exologia, mass agem sueca e shiatsu. A shantala era desenvolvida uma vez por mês para um grupo de gestantes em uma das unidades. Havia pouca uniformidade s obre o con cei to de massagem e sua aplicação; para alguns profissionais, o termo massagem não incorporava o shiatsu. Quando perguntamos que ti po de massagem faziam, eles responderam: A gente não usa nenhuma dessas chinesas e indianas, a gente usa a massagem sueca e terapêutica dentro do programa... a reflexologia também. (profissional 1)

$E$, a gente faz a massagem sueca, não sei se você está incluindo o shiatsu, acho que não, porque o shiatsu é uma técnica diferen te, e a refl lexologia, os pés diabéticos ou probl emas circulatórios. (profissional 4)

A prática do shiatsu foi denominada pelos en trevistados também como: catakuri, e shiatu expresso, entre outros, como se fosse a mesma a tivid ade. Para Maki (2003), as variações e nomes dados ao shiatsu não atendem ao seu obj etivo, não é fundamen tado nos meridianos e na ci ralação de Qİ. Essa prática requer aprofundamen to no problema e bastante atenção do terapeuta tanto no diagnósti co quan to na sua utilização. Para o autor, não é possível realizar uma massagem adequada em 15 ou 30 minutos.

Catakuri, a massagem terapêutica... e a reflexologia, especialmente pa ra os diabéticos que eles têm problemas de circulação. (profissional 5)

Por sua vez, a reflexologia estava sen do empregada principalmente para probl emas circu- latórís e o "pé diabéti co"; não aproveitada, portanto, como um rel evan te método de diagnóstico e de prevenção. Estava sendo tratado o problema local (circulação), fazendo pouca referência à utilização das zonas de reflexo, próprias da refl exologia.

Percebemos durante a observação participante que as técnicas utilizadas na realização da massagem estavam ligadas mais à massagem sueca (massagem ocidental).

A adaptação das práticas de massagens ori entais era uma realidade observada nos serviços de saúde. Nes te caso, p a recia estar mais ligada a uma submissão ao modelo hegemônico, uma vez que, na prática da massagem, os parâmetros do modelo biomédico foram os utilizados. Não se trata de negar uma possível adaptação, mas avaliar de que maneira as ad aptações ocidentais desvirtuam-se do real obj etivo da mass a gem de s ca racteriza n do-a e distanciando-a de s eus fundamentos, o que poderá implicar result ados menos favorá veis. Con tudo, prom over espaços favorá veis ao uso das práticas alternativas nos serviços de saúde é favorecer a oferta de outras tec nol ogias de tratamen to bem com o, a reva lorização do campo simbólico esqu eci do pela medicina. Para Nascimen to (1998), a tentativa de acomodar as práticas alternativas do modelo biomédico revela uma dificuldade epistemológica deste em se confrontar com outras formas de conhecimen to. Como também uma estratégia que visa evitar a con corrência entre sistemas médicos distintos, para preservar a a utoridade cultural da medicina convencional e o mon opólio médico, submeten do e con trolando aqu elas práticas que alcançam significativa aceitação social.

\section{Fragm entação $\mathrm{X}$ abordagem integral}

Não foi visto nos serviços o acompanhamento diagnóstico por meio da medicina tradicional chinesa, avaliando o excesso ou deficiência de Qİ. As indagações sobre comportamento e emoções eram restritas. Apenas em dois serviços havia informações nas fichas dos u suá rios sobre esses aspecto s. A leitura - termo utilizado por Merhy (1994) quan do faz alusão ao diagnóstico - através das tecnologias da medicina ori ental era pouca ou não realizada, predominan do o diagnóstico do modelo biomédico. Percebemos que esta adaptação foi esti mulada pela pró pria história do programa, ou se$\mathrm{ja}$, a tender à demanda de usuários com doenças crônicas. No entanto esta adequação para 
o modelo biomédicose con trapõe ao paradigma vitalista, na medida em que apenas en foca as doenças. Apesar de os profissionais terem sido capacitados para uma abordagem integral dos indivíduos, a atenção era dada à doença. Ne s te cenário, o que obs ervamos foram ações conflituosas e distintas entre os profissionais diantedas qu eixas dos usuários:

Essa dor é com o dinico, meu problema com você é só seu punho e sua cervical, que estou vendo que está tudo bem. (profissional 3)

Tudo começou de dentro, tudo começa na emoção, se a gente estivesse bem não levava trombada. (profis sional 4)

Assim, de acordo com Quei roz (2003), a fra gm entação do indivíduo e o enfoque dado à doença e não ao doen te têm sido características presen tes da medicina ocidental moderna, e predominam no co tidiano das instituições. É comum nos serviços públ i cos haver certa pre ssão para que as práticas altern a tivas ad a ptemse ao modelo biomédico, como acon tece com a homeopatia e, segundo Luz (1998), com a acupuntura.

É importante analisar as práticas assistenciais na perspectiva de um outro olhar sobre o processo saúde-doença, buscando construir a in tegralidade. Compreender o doente parece ser um caminho eficiente para o cuidado, talvez seja isto que muitos usuários estejam buscando nos serviços: um cuidado integrador.

\section{Encaminhamentos, percu rso nos serviços}

Após terminar o tratamen to com algum tipo de massagem ou auriculoterapia, o usuário con tinu ava no programa pratican do ginástica, caminhada ou oficina de relaxamento (a oficina era oferecida em apenas uma das unidades). A caminhada e a ginástica deveriam atuar, também, como "porta de entrada" para a massoterapia, como afirma a geren te: Nós estamos tentando fazer este ti po de integração, o paciente hipertenso é encaminhado pa ra a ginástica... com isso a gente já tem um bom resultado... ter um grupo social... tudo isso faz com que ele volte a se integrar... Aí o profissional vai observar quem é que tem mais dificuldade e vai precisar de um trabalho mais individual.

O perfil da demanda era influenciado pelo encaminhamento. Em todos os serviços, o maior número de encaminhamen tos vinha da própria unidade, tanto por parte dos programas de hipertensão, diabetes e idosos, quanto pelos seus profissionais. Receber encaminhamento de outros profissionais poderia significar algum avanço qua n to à val orização da massa gem. No en tan to, alguns massotera peutas começaram a requ erer dos usuá rios que solicitassem o encaminhamento dos médicos, pois, segundo eles, isso dava uma certa segurança. Para os indivíduos com hipertensão ou problemas cardíacos realizarem algumas atividades, principalmente a caminhada e a ginástica, era preciso a autorização médica. Em um dos serviços, o encaminhamento começou a ser obrigatório a partir de setem bro de 2003 .

Dificilmen te ele está aqui só fazendo isso, ele sem pre está na unidade fazendo alguma atividade... até mesmo porque o pro gramaexige... quando não tem nada, ele vem me procu rar e é ori entado a se inscrever, abrir prontuário para anamnese... quem tem problemas cardíacos solicito uma co nsulta com o cardiologista. (profissioml 1)

Vem daqui mesmo, encaminhada pelo pessoal da fisio e do serviço social e a gen te também encaminha e ago ra o pessoal dos médicos e principalmente uma determinada psiquiatra... e doutor, a cho que é fisiatra, homeopata também. (profissional 5)

Depen dendo das condições do paciente, se eu vir que um paciente não está mel ho rando com o tratamen to eu encaminho ele novamen te pa ra o dinicoque me encam inhou... essa relação deles está mel horando... ele volta ao médico pa ra ter esse acompanhamento em conjunto (profissional 2)

A interação dos profissionais do programa e os outros prof i s s i onais de saúde é crucial e relevante. Porém, esta comunicação deve favorecer o intercâmbio de conhecimentos e não o predomínio, dependência ou submissão. Todos os profissionais, notadamente os biomédicos, enfatizavam bastante a necessidade de consultas médicas. As falas que se seguem abordam a pressão que recebiam por parte de outros profissionais, principalmente médicos. Podemos observar que diferem das anteri ores, trata-se de um diálogo duran te um dos even tos prom ovidos pelo programa, releva $n$ do aspectos não express ados duran te as en trevistas. Como afirma Mi n ayo (1992), não podemos perder de vista o con tex to em que a fala é produzida, duran te o even to eles se sentiam mais à vontade em falar de suas dificuldades:

Eles parecem que estão dormindo, mas na hora que a gen te precisa eles caem em cima. (profissional 1)

Temos muito cuidado, sempre pedimos pa ra que eles passem no médico... de preferência mé- 
dico, mas pode ser da psicol o gia, en fermagem, fisio... (profissional 3 )

\section{Os usuários: qu em são e por que utilizam a massagem}

Ao analisarmos o número de usu á rios por unidades, notamos uma distribuição linear. Esta distri buição é porém assimétrica en tre os profissionais. En contramos prontuários em apenas uma unidade; para as ativid ades do programa era utilizada uma ficha específica que continha alguns dados dos usuários. Assim, para esse estudo foram analisadas todas as fichas disponíveis do período pesquisado sendo: 277 fichas das quais 75 pertenciam à policlínica; 122, fichas ao hospital; e 80 fichas corres ponden tes aos dados dos dois profis si onais pesquis ados em um po s to de assistência médica.

\section{Classe social e grau de instrução}

Nas fichas não con st ava renda e/ou grau de instrução, apenas profissão atual. Então, analisamos os dados de profissão e verificamos que gra n de parte dos usuários era apo s en t ada (40\%). Entre aqueles que trabalhavam, a maioria des em pen h ava funções de nível médio, não sendo possível afirmar sua formação superi or. Diante de tal em pecilho, buscamos estes dados com os profissionais, segundo os quais poucos dos usuários tinham grau de instrução superior. Entre estes se destacavam os profissionais que trabalhavam nas unidades e eram atendidos pelo programa.

A maioria dos usuários vinha de áreas pobres e queixava-se bastante da violência. Era comum falarem das dificuldades on de moravam, da pressão que sofriam pelo tráfico de $\mathrm{d}$ rogas, do medo em que viviam, da perda dos filhos, entre outros. Como elucida Va lla (2001), nas grandes cidades as classes populares tendem a sofrer um processo de estresse mais intenso. Mas havia um público com melhores condições econômicas que procurava o aten $\mathrm{d}$ imento afirmando que os planos de saúde não ofereciam este tipo de terapia. Este fato torn ava a demanda mista em relação à classe social e econômica, como revelam as falas dos profissionais:

Quando vi, ela chegou em um carro importado. (profissional 5)

No fim do mês é pior, pois eles não têm dinhei ropara pegar o ônibus. (profissional 13)
Descobri que duas pacientes têm planos de saúde bons e vêm se tratar aqui. Eu perguntei, mas aí você tem plano... é mais lá não sou tratada como sou aqui, não tem a mesma coisa que tem aqui. (profissional 2)

\section{Gênero e idade dos usuários}

Cotidianamente, as mulh eres buscam mais os serviços de saúde que os homens, seja por fatores biológicos, por fatores cultu rais ou pela or ganização dos serviços. Na busca pelas práticas alternativas não foi diferente; em todas as unidades de saúde o sexo feminino predominava, corre s pon den do a (87 \%) do total.

Encon tramos um maior número de usuários a partir de 51 anos, o que pode ser explicado pelo fato de o objetivo inicial do programa s er voltado para doenças crônicas. $\mathrm{O}$ aumen to da procura de práticas altern a tivas por pessoas de outras faixas etárias talvez esteja revelando que existe outra parcela da população que deseje ser atendida. Porém, a maneira como tem sido ofertado, pode ter provocado a supressão de outras faixas etárias. É importan te que seja considerada essa relação tanto na análise da faixa etá ria quan to na dos motivos de procura, que podem ser verificados na tabela 1 .

\section{Motivos e indicações}

Para visualizarmos os motivos/indicações que levaram estas pessoas a buscarem a massagem agregamos os motivos à medida que eles apa reciam nas fichas cadastrais. Assim, foram estabel ecidos qu a tro grupos, denominados pelas queixas escritas nas fichas e separados pela freqüência e aproximação de sintomas: 1) dores - artralgias, artrite, a rtrose, dores músculoesqueléticas; 2) doenças crônico-degen erativas, especificamente hipertensão e diabetes; 3 ) sistema nervoso alterado - estresse, ansiedade, n ervosismo, medo, depressão; 4) e outros motivos - apareceram com men or freqüência, sendo um ou dois casos nas unidades, como gastrite, obesidade, varizes. Os motivos e as indicações podem ser visualizados na tabela 2 .

O mesmo usuário poderia apresentar mais de um motivo ou indicação. Entretan to é expres sivo o aparecimento de motivos relacionados ao sistema nervoso e às qu eixas de dor. Talvez este fato revele que as causas que motivaram a proc $u$ ra de alternativa foram aqu elas que não puderam ser resolvidas pelo modelo biomédico, não restando outra opção, a não ser en- 
Tabela 1

Distribuição percen tual dos usuários por faixa etária por profissionais e unidades que oferecem a prática de massagem na AP 3.1 do Município do Rio de Janei ro, de zem bro, 2003.

\begin{tabular}{|c|c|c|c|c|c|c|c|c|c|c|}
\hline \multirow[t]{2}{*}{ Idade em anos } & \multicolumn{2}{|c|}{ Profissional 1} & \multicolumn{2}{|c|}{ Profissional 3} & \multicolumn{2}{|c|}{ Profissional 4} & \multicolumn{2}{|c|}{ Profissional 5} & \multicolumn{2}{|c|}{ Total } \\
\hline & $\mathrm{N}^{\circ}$ & $\%$ & No & $\%$ & No & $\%$ & No & $\%$ & No & $\%$ \\
\hline 11 a 30 & 01 & 2 & 03 & 3 & 02 & 5 & 02 & 5 & 08 & 3 \\
\hline 31 a 50 & 11 & 14 & 35 & 29 & 08 & 20 & 15 & 37 & 69 & 25 \\
\hline 51 a 70 & 51 & 68 & 58 & 47 & 21 & 54 & 16 & 39 & 146 & 52 \\
\hline 71 e mais & 12 & 16 & 26 & 21 & 08 & 21 & 08 & 19 & 54 & 20 \\
\hline Total & 75 & 100 & 122 & 100 & 39 & 100 & 41 & 100 & 277 & 100 \\
\hline
\end{tabular}

Tabela 2

Freqüência dos motivos e indicações para massagem dos usuários com menos de 50 anos e mais de 50 anos, por profissionais e unidades que oferecem a prática de massagem na AP 3.1 do Município do Rio de Janei ro, de zem bro, 2003.

\begin{tabular}{|c|c|c|c|c|c|c|c|c|c|}
\hline \multirow[t]{2}{*}{ Grupo } & \multicolumn{2}{|c|}{$\begin{array}{c}\text { Profissional } 1 \\
\text { PJPF }\end{array}$} & \multicolumn{2}{|c|}{$\begin{array}{c}\text { Profissional } 3 \\
\text { HPW }\end{array}$} & \multicolumn{2}{|c|}{$\begin{array}{c}\text { Profissional } 4 \\
\text { PCP }\end{array}$} & \multicolumn{2}{|c|}{$\begin{array}{c}\text { Profissional } 5 \\
\text { PCP }\end{array}$} & \multirow{2}{*}{$\begin{array}{c}\text { Total } \\
\text { Todas idades }\end{array}$} \\
\hline & 50 anos & $<50$ anos & 50 anos & $<50$ anos & 50 anos & $<50$ anos & 50 anos & $<50$ anos & \\
\hline Dores & 6 & 35 & 51 & 20 & 21 & 5 & 15 & 3 & 156 \\
\hline $\begin{array}{l}\text { Doenças crônicas } \\
\text { degen erativas }\end{array}$ & 2 & 46 & 47 & 8 & 19 & 6 & 7 & 6 & 141 \\
\hline Sistema nervoso & 4 & 19 & 32 & 19 & 26 & 1 & 7 & 3 & 111 \\
\hline Outros motivos & 4 & 12 & 13 & 2 & 3 & 0 & 4 & 3 & 41 \\
\hline
\end{tabular}

caminhar o usuário para a massagem, con forme referem os massotera peutas.

Ela não tinha o que fazer, e estava buscando um recurso pa ra melho rar a dor do paciente. Então, ela apo s tou mui to no meu trabalho. (prof issi onal 3)

Ela queria fazer um trabalho comigo... a gente ia sentar pa ra convers ar, mas era algo com respeito a zumbidos que os pacientes têm que ela não sabe bem a causa. (prof is sional 5)

As indicações são para diminuir o estresse muscular, é estre semesmo do dia-a dia, dá uma relaxada, pe soas de muita idade que têm dores na coluna, probl ema circulatório. Aí a gen te faz uma massagem pa ra dar um alívi o. (profissioml 4)

Valla (1999) chama a atenção para o fato de a população estar manifestando seu adoecimento através do "sofrimento difuso" expres$s$ ado por ansied ade, depressão, nervosismo. Segundo Pinhei ro \& Luz (2003), nas instituições de saúde, a oferta e a demanda têm sido ao longo dos anos organizada por uma lógica bi om édica em que a ênfase é dada à doença e muitas vezes o tratamento descaracteriza e desperso- naliza o indivíduo. Por isso, é possível que as práticas alternativas venham a contribuir com re sult ados mais satisfatórios.

Pa ra que isso aconteça, porém, é necessário permitir seu verd adei ro uso. São po u cos os estudos que demonstram os benefícios para os usuários que utilizam outras terapias e que são atendidos nos serviços por meio de outras racionalidades médicas. É preciso que os resultados das pesquisas que proc u ram evidências de eficácia con si derem também de que manei ra as práticas altern a tivas estão sen do empregadas e que métodos de avaliação estão sendo utilizados. Vale lembrar que os métodos científicos utilizados atualmente foram criados para avaliar e verificar os efeitos da biomedicina e que estes, muitas vezes, ao serem utili z adospara práticas fundamen tadas em outro paradigma, não são capazes de apreender todos os aspectos simbólicos envo lvi dos na busca pela cura. Os estudos, nesse caso, deveriam levar em conta outro tipo de eficácia além da redução de custos para os serviços, avaliar se a assistência está responden do às ex pect a tivas do indiví duo doen te. 


\section{Significados para o usuário}

Nosso objetivo era apenas apontar o perfil dos usuários por meio dos prontuários. Todavia, nas visitas às unidades durante os atendimentos, os usuários demonstravam ansiedade quanto à nossa presença e ten tavam expressar a im portância das atividades para eles. Is to revela também que por mais sutil que seja o pesqu is ador ele interfere no seu obj eto.

Os usuários pareciam ac reditar que de algum modo pudéssemos con tribuir com o programa e se mostraram colaborativos. Apontavam aspectos positivos do tratamento e do profissional que os atendia, contavam seu percurso até en contrar o tratamento e de como este havia sido importante para sua saúde. Tentavam dem on strar que estavam satis fei tos com as a tividades e como haviam influ en ciado suas vidas. Deste modo, optamos por elucidar falas que repres entam a maioria das ex pressões que anotamos no diário de campo ou gravamos durante a observação participante. Para aprofundarmos e analisarmos a percepção dos usuários, sabíamos que deveríamos dispor de mais d ados, porém a coleta não foi possível em virtude dos limites necessários que conferimos a e s te estu do. Nesse sen ti do, as falas apresentadas constituem uma aproximação dos "significado s" da massagem para os usuários:

Faz tão bem que se eu pudesse não sairia mais daqui;passava a vida toda. (usuária 1)

Ele curou minhamulher, é um Deus para ela. (usuário 2)

Quando sinto alguma coisa venho aqui... não posso dizer que ela resolve tudo, mas é milagrosa... ela me ensinou uma coisinha daqui, outra dali e olha meu pé, está até mexendo. (usuária 4)

Para os usuários, a cura nem sem pre estava relaci on ada ao aniquilam en to de alguma nosologia específica. Ela era ex pressa como os ben efícios que estavam sen do alcançados du ran te o tratamen to. As atividades significavam também interagir com outras pessoas, ser toc ado por alguém. As pequenas conquistas, como conseguir deitar na maca sem ajuda, levantar um braço, m el horar de alguma dor, fazer caminhada, eram con si deradas cura. Eles con tinuavam buscando o tratamento para se manterem saudáveis.

No paradigma vitalista, saúde necessariamen te não se contrapõe à ausência de alguma doença. O equilíbrio do Qİ no indivíduo, segundo Queiroz (2000; 2003), é a harmonia nas relações sociais e com o meio ambi en te que re- presenta estar saudável. Assim, um tratamen to altern a tivo requer dos indiví duos uma mudança na con cepção de saúde e doença, uma alteração no sentido da própria vida, envolvendo sua dimensão emocional e seus valores mais íntimos. Nesse senti do, a cura pre supõe valores culturais, políticos e sociais, e seu sentido pode ser modificado dependen do de onde se está inseri do.

Percebemos que o significado de cura manifest adopelos usu á rios parecia estar mais próximo dos fundamen tos do paradigma vitalista. A maioria dos usuários con ti nu ava doen te para a racionalidade biomédica. Eram hipertensos e diabéticos, porém afirm avam estar saudáveis e elu c i d avam que, depois do tratamento no programa, sua relação com as pessoas havia mud ado.

\section{Os profissionais: qu em são e o que pensam sobre a massagem}

\section{Vínculo e formação do massoterapeuta}

Todos os profissionais pesquisados eram efetivos da Secretaria Municipal de Saúde. Quatro deles eram concursados como massoterapeutas e um era auxiliar de enfermagem que atuava como auxiliar da fisioterapia, sendo desviado desta função para se tornar massoterapeuta. Dos entrevistados, um era formado em fisioterapia, três estavam em formação na mesma área, e outro era auxiliar de enfermagem. Três eram do sexo feminino e dois do sexo masculino. A média de tem po como massoterapeuta nas unidades de saúde era de dois anos. Três deles realizavam massagem há mais de cinco anos. Os profissionais entrevistados h aviam participado dos cursos de massagem oferecidos pela geren te do programa. Quatro deles tinham realizado curso técnico em massagem em institutos e escolas. Apenas um dos profissionais, o que não tinha curso técnico em massagem, já havia aplicado técnicas de medicina altern a tiva antes de en trar no programa.

\section{Conhecimentos empregados}

Quanto aos fundamentos das práticas, existia uma combinação en tre modelo biomédicoe conhecimentos de outras racion alid ades. Aqueles profissionais que já tinham nível superior na área de saúde ou estavam se graduando, empregavam com maior freqüência os pressupos- 
tos biomédicos. Apenas dois falaram sobre o Qİ ou energia, quando perguntamos quais os conhecimentos que utilizavam para a prática da massagem.

A gente vai conhecendo as técnicas novas, acaba fazendo uma misturinha ... a gente está fazendo uma reflexologia, a pessoa se queixa de cãibra, e você vai lá no pontinho F3, vai ajudar na ci rulação da perna, isso é auto mático não dá para fazer separado, a gente tem que misturar. (profissional 4)

$E$ da medicina tradicional chinesa, dos cinco elementos, é yin, yang e dos canais energéticos. (profissional 3)

Conhecimen tos de anatomia, é isso que você quer saber?... Tem que saber a direção das fibras e da ci rculação e também dos pontos ali da carta de reflexologia, os mapas de auriculoterapia. (profissional 5)

Dura nte $o$ aten dimen to e as en trevistas, como revela a primeira fala, os con hecimen tos se entrelaçavam. Às ve zes o profissional que dizia não utilizar os con h eci im en tos da medicina ch inesa fazia orientações que diziam respeito à mesma. Os conhecimentos utilizados pareciam estar mais ligados à operaci onalização das práticas de massagem que aos significados ou ao paradigma que as fundament ava. A fala abaixo, decorrente de um momen to da observação participante, revela essa dialética:

É uma lavagem cereb ral a história da Medicina Tradicional Chinesa, po rque é totalmente diferen te dessa aqui; mas se a pessoa quiser chegar a isso. (profissional 5)

\section{In teração com o usuário}

Pa rece que as práticas de medicina alternativa prom ovem uma satisfação e bem-estar nos usuários dificultando o distanciamen to e a alta. Em estudo realizado por Luz (1999), os profissionais que aplicavam acupuntura abordavam este aspecto. Isto também ocorria com a massagem:

O toque da massagem faz com que a pessoa fique muito dependente. Essa semana uma senhora falou assim: a senhora não vai fazer aquela massagem nos pés? É tão boa. (profissional 3 )

Dentro do tratamen to, a ginástica e a caminhada são livres, mas a reflexo, a massagem e a aurículo são dez sessões. O difícil é dar alta ao pacien te que quer sem pre continuar. (profissional 1)

A ginástica e a caminhada eram utilizadas como uma maneira de o usuário satisfazer a necessidade de continuar sendo tratado. Alguns grupos de ginástica e caminhada se consolidavam, levan do alguns profis si onais a realizar outras ativid ades como anivers á rios e datas comemorativas.

Dura nte $o$ atendimento, havia alguns usuários que o massotera peuta escutava mais, estimulava para que eles falassem sobre seus problemas e buscassem soluções. Eles revel avam que sabiam que algumas pessoas só desejavam s er ouvidas. A disponibilidade dosprofission ais para tentar resolver os probl emas dos usuários revelava a possibilidade de mel horar a qualidade das ações des envo lvidas nos serviços de saúde. Mesmo que não pudessem realizar o tratamen to, eles sem pre prestavam alguma assistência, fazen do auriculoterapia ou ouvindo as queixas. Existia uma interação no encon tro do profissional com os usuários que se transformava a cada instante. Merhy (1994) discute a necessidade do desenvolvimen to da tecnologia leve nos serviços de saúde e o fortalecimen to do trabalho vivo em saúde. $\mathrm{O}$ autor defende a con strução de um vínculo en tre usuário e profissional que ga ranta o acesso às ações de saúde e que permita a oferta de múltiplas opções tecnológicas para enfrentamen to dos diferentes problemas. Entre as ofertas tecnológicas a tecnologia leve (a manei ra de lidar com o usuário) seria aqu ela de grande valia para a recuperação do usuário. De acordo com Lacerda e Valla (2003), a relação entre o profissional de saúde e o usuário vem sen do apon tada como um dos gran des pilares na eficácia do tratamento. Deve ser construída uma relação que possibilite a apreensão das narra tivas dos usuários, repletas de sen ti dos e significados.

\section{Buscan do compreen der as qu eixas dos usuários}

A reduzida pad ronização, normatização das ações por parte da gerência do programa, possibilitava maior liberdade de atuação permitindo que alguns profissionais individualizassem sua prática utilizando mais de um ti po de tratamento. Apesar de não usarem explicitamente o diagnóstico da MTC ou da reflexologia para escolha da terapia, eles se mostravam sensíveis a ouvir as diversas queixas dos usuários. Bu scavam en ten der outros significados para a doença a partir dessa queixa. Este fato pode ser exemplificado por meio de dois profissionais quando faziam a reflexoterapia e a auriculoterapia: 
Vi o nível de estre se dela com o sumiço do filho, com o espo so acamado; então, re solvi fazer a aurículo também. (profissional 2)

Você viu que ela referen ciou a massagem enquan to fazia a aurículo e fui fazer porque se não ela piorava. Ela estava acostumada ao toque e agora não tem mais. Quando alguém refere a dor vou logo tocando. Você tem que ficar aten to pa ra todas as queixas... Não é assim que a cabeça funciona; se a gen te não cuida piora. (profissi onal 4)

Apesar das dificuldades observadas em se adotar a prá tica da massagem usando as teoria s do parad i gma vitalista, os profissionais dem on straram pela escuta que o primeiro passo já tinha sido dado, já haviam começado a con s truir um espaço para que essas teorias pudessemse de s envo lver. A indivi dualização do tratamento permitia que o usuário pudesse ser atendido dentro de sua verdadeira necessidade. Assim, corroboramos com o estu do de caso realizado por Si lva Jr. et al. (2003), o qual demonstra como é possível con s truir novos arranjos no co tidiano dos serviços de saúde a partir de um projeto terapêuti co individualizado

\section{Considerações finais}

São muitos os fatores que contribuem para o descompasso en tre os fundamen tos teóricos e a concretização das ações. No que se refere à massagem, mesmo sendo implantada pelo Programa de Medicina Al tern a tiva, fundamentado em um paradigma vitalista, ao intera gir com a dinâmica dos serviços sua ação conver gia para o utras teorias. As categorias de análise teóricas e empíricas revelaram vários momentos de conflito en tre teoria e práxis.

Embora este estudo tenha revelado a predominância do paradigma biomédicona prática da massagem nos serviços de saúde, os resultados apontaram que a sua demanda tem a u men tado não só para o tratamen to de doenças, foco inicial do programa.

Revela também que os ben efícios relatados pelos usuários são expressivos. Sinaliza o potencial que o programa de medicina altern a tiva tem para a promoção de espaços favorá veis ao uso de outras racionalidades. Ac reditamos que a expansão dessas práticas se constitui num processo a ser construído e avaliado, revendo os objetivos para que realmen te se torne uma alterna tiva de aten dim en to e mel horia da assistência no SUS.
O crescimento da Medicina Alternativa, mesmo sendo uma realidade cada vez mais pres en te nos serviços de saúde, apresenta grandes desafios para sua institu c i onalização tais como: redu $\mathrm{z}$ i donúmero de rec u rso humano capacitado; insuficiente financiamento para a maioria das práticas; e poucos espaços institucionais $\mathrm{p}$ a ra seu desenvo lvi $\mathrm{m}$ en to nos serviços. Por outro lado, a incorporação do parad igma vitalista provoca a discussão dos limites e das insuficiências estruturais do paradigma científico m odern o, o que leva à constituição de mais um desafio na sua incorporação.

Tod avia, não basta os governos insti tuírem nos sistemas oficiais a medicina alternativa ou mesmo a promu l gação legal para ga ra $n$ tir a sua oferta com qualidade. Foi o que constatamos no nosso estu do e que tem confi rmação no estu do de Nigenda et al. (2001), os quais relatam s obre a prá tica e a regulação da medicina tradicional em nove países da América Latina e Caribe. Faz-se necessário promovermos espaços de discussão tanto no âmbi to ac ad ê mi co quanto nos serviços, considerando as dificuldades para o uso de um "n ovo" paradigma no cuidar.

No entanto, não podemos ser simplistas a pon to de reduzir as dificuldades encontradas em implantar uma prática "nova" por ela estar fundamentada em teorias distintas do modelo predominante. Devemos considerar também que normalmente os indivíduos apresentam resistência em relação ao "n ovo"; is to pode ser vi s totambém quando são utilizadas novas descobertas no campo do modelobiomédico.

Para se construir um sistema em que haja maior participação do usuário é importante com preender que é necessário estimular o indivíduo a participar e en ten der a sua doença, a gestão de si mesmo. É preciso também ampliar o processo de compreensão do indivíduo, da doença, da saúde, da vida e analisar as práticas assistenciais na perspectiva de um outro olhar s obre o processo saúde - doença, para, desta maneira, de s envo lver uma abord a gem integral nas ações de saúde.

Buscar outra compreensão do processo de adoecimen to con s ti tui um desafio a ser su perado no dia-a-dia das instituições de saúde. Principalmente por aqueles que dão vida ao sistema: os profissionis de saúde. É a partir destes que se poderá con formar outra manei ra de cuidar. O de senvo lvimento das práticas alternativas requer que, nestes espaços favoráveis, es tejam presen tes as mudanças no modo de agir dos profissionais, por demandar uma grande 
transformação na concepção de saúde e doença e, conseqüentemente, na maneira de cuidar/curar o doen te.

O processo de implantação do Programa de Medicina Al tern a tiva e, es pecificamente, da massagem demonstrou que existem muitos profissionais que buscam mel h orar a assistência e empregam todos os seus esforços. Observamos que apesar de estarem empregando no fazer cotidiano uma prática distinta daqu ela que era a pregoada pelo programa, os massoterapeutas mostraram-se sensíveis às queixas dos usuários. Nesse sentido, é possível que a dificuldade em lidar com os sintomas subjetivos possa ser superada por esses profissionais.

\section{Colaboradores}

IMC Sousa planejou e redigiu o artigo, realizau a discussão, o aprim ora m en to e a revisão final do tex to. ALS Vi eira planejou e redigiu o artigo, realizou a discussão e o a primoramento do tex to.
Dian te das dificuldades encon tradas no programa, fa zemos algumas sugestões: capacitação teórica e prática dos massoterapeutas; reformulação das fichas cadastrais e dos relatórios mensais; mudança na informação da massagem como atividade de grupo; e encaminham en tomais flexível para maior acessibilidade.

Ao mesmo tempo em que existe a carência de estudos científicos que analisem as práticas al tern a tivas, es te fato parece ser utilizado como justificativa para que as mesmas não sejam incorporadas aos serviços de saúde. Con tu do, ao se buscar a legi timação da medicina altern a tiva por meio de pesquisas, devemos considerar as especificidades do parad igma vitalista em suas dimensões e dificuldades para o desenvolvimen tode suas práticas.

\section{Agradecimentos}

À Fundação de Amp a roà Pe s quisa do Rio de Ja n ei ro pelo apoio financeiro; ao Grupo de Pesquisa Racionalidades Médicas da UERJ pelo acervo teórico e ao Programa de Medicina Alternativa da Sec retaria Municipal de Saúde do Rio de Janei ro pelo acolhimento. 


\section{Referências bibliográficas}

Bontempo M 1994. Medicina Chinesa. Guia Prático de Med i cina Natural. Nova Cultural, São Paulo.

Capra F 1998. O pon to de mutação. EditoraCultrix, São Paulo.

Frei re M 1993. Conhece-te a ti mesmo: uma proposta de educação popular para a saúde. Saúde em Deba te 41: 4-9.

Frei re M 1996. Automassagem e medicina chinesa. Indepen den te, Brasília.

Godoy AN 1988. O toque como parte da ação do processo de rel acionamentoen fermeiro-paciente. Tese de livredocência. Faculdade de Enfermagem-Un iversidade Estadual do Rio de Ja n ei ro.

Jacques LM 1999. Massoterapia. Insti tuto de Acupuntura do Rio de Jan ei ro.

Lacerda A \& Valla VV 2003. Homeopatia e apoio social: repensando as pr á ticas de integralidade na atenção e no cuidado à saúde, pp. 169-196. In R Pinhei ro \& RA Mat tos( orgs.). Construção da integralidade: cotidiano, saberes e práticas em saúde. Abrasco, Rio de Janei ro.

Loyola MA 1987. Uma medicina de classe média: idéias prel im in a res sobre a cl i en tela da hom eop a tia. Cadernos do IMS 1:45-72.

Loyola MA 1991. Medicina tradicional e medicinas alterna tivas, pp. 125-133. In D Bu ch ill et ( org.). Medicinas tra di cionais e med i cina ocidental na Amazônia. MPEG, CNPq, SCT, Cejup, UEP, Belém.

Luz D 1993. Racionalidades médicas: med icinatradicional chinesa. Universidade do Estado do Rio de Janei ro Instituto de Medicina Social (Série Estu dos em Sa úde Coletiva, 72).

Luz MT 1996. Estudo comparativo das medicinas ocidental contemporânea, homeopática, tradicional chinesa e ayurvédica em programas públicos de saúde. Un ivers i$\mathrm{d}$ ade do Estado do Rio de Jan eiro, In s ti tuto de Medicina Social (Série Estu dos em SaúdeCol etiva, 140).

Luz MT 1999. Comparação de representações de corpo, saúde, doença e tratamento em pacientes e terapeut as de homeopatia, acupuntura e bi omedicina. PHYSIS: Revista Saúde Col etiva

Maki R 2003. A implantação de massagem. Entrevista. (Mimeo)
Merhy EE 1994. Em busca da qualidade dos serviços de saúde: os serviços de porta aberta para a saúde e o modelo técnico assistencial em defesa da vida, pp. 117-160. In LCO Cecílio (org.). Inventando a mudança na saúde. Hucitec, São Paulo.

Mi n ayo MCS 1992. O desafio do conhecimento: pesquisa qualitativa em saúde. Hucitec-Abrasco, São PauloRio de Ja neiro.

Nascimento MC 1998. De panacéia mística a especialidade médica: a acupuntura na visão da imprensa. História, Ciê n cias e Saúde 1:99-113.

Nigenda G, Mora-Flores GM, Aladma-López S \& Orozco-Nunez E 2001. La prática de la medicina tradicional en América Latina y el Caribe: el dilema en tre regulación y tolerancia. Salud Pública de México 43(1):41-51

Pinhei ro R \& Luz MT 2003. Práticas eficazes x modelos idéias: ação e pen sam en tona con strução da in tegralidade, pp. 7-34. In R Pinheiro \& RA Mat tos (orgs.). Construção da integralidade: cotidiano, saberes e práticas em saúde. Abra sco, Rio de Janei ro.

Queiroz MS 2000. O itinerá rio rumo às medicinas alternativas: uma análise em representações sociais de profissionais da saúde. Cadernos de Saúde Pública 16: 363-375.

Quei roz MS 2003. Saúde e doença: um enfoque antropológico. Edusc, Ba uru.

Si lva Jr AG, Merhry EE \& Carvalho LC 2003. Refletindo sobre o ato de cuidar da saúde, pp. 113-128. In R Pinhei ro\& RA Mat tos (or gs. ). Construção da integralidade: cotidiano, saberes e práticas em saúde. Abrasco, Rio de Jan ei ro

Svoboda R \& Lade A 2000. Tao e Dharma: medicina chinesa e ayu rved $a$. (Trad. Edu a rdo P. Ferrei ra). Editora Pensamento, São Paulo.

Valla VV 1999. Educação popular, saúde comunitária e a poio social numa conjuntura de globalização. $\mathrm{Ca}$ dernos de Saúde Pública 15:7-14.

Valla VV 2001. Globalização e saúde no Bra s i l: a busca da s obrevivência pelas classes popular via questão rel igiosa, pp. 39-62. In EM Vascon celos (org.). A saúde nas pa lavras e nos gestos. Hucitec, São Paulo.

Artigo apresen tado em 6/01/2005

Aprovado em 11/04/2005

Versão final apresen tada em 2/06/2005 